Published in final edited form as:

Clin Cancer Res. 2020 January 15; 26(2): 439-449. doi:10.1158/1078-0432.CCR-19-1667.

\title{
Co-occurring alterations in the RAS-MAPK pathway limit response to MET inhibitor treatment in MET exon 14 skipping mutation-positive lung cancer
}

\author{
Julia K. Rotow ${ }^{1,2}$, Philippe Gui ${ }^{1,2}$, Wei Wu ${ }^{1,2}$, Victoria M. Raymond ${ }^{3}$, Richard B. Lanman ${ }^{3}$, \\ Frederic J. Kaye ${ }^{4}$, Nir Peled ${ }^{5}$, Ferran Fece de la Cruz ${ }^{6}$, Brandon Nadres ${ }^{6}$, Ryan B. \\ Corcoran $^{6}$, Iwei Yeh ${ }^{2,7}$, Boris C. Bastian ${ }^{2,7}$, Petr Starostik ${ }^{8}$, Kimberly Newsom ${ }^{8}$, Victor R. \\ Olivas $^{1}$, Alexander M. Wolff ${ }^{9}$, James S. Fraser ${ }^{9}$, Eric A. Collisson ${ }^{1,2}$, Caroline E. \\ McCoach $^{1,2}$, D. Ross Camidge ${ }^{10}$, Jose Pacheco ${ }^{10}$, Lyudmila Bazhenova ${ }^{11}$, Tianhong Li ${ }^{12}$, \\ Trever G. Bivona ${ }^{1,2,13}$, Collin M. Blakely ${ }^{1,2,13}$ \\ ${ }^{1}$ Department of Medicine, University of California, San Francisco, \\ ${ }^{2}$ Helen Diller Family Comprehensive Cancer Center, University of California, San Francisco, \\ ${ }^{3}$ Guardant Health, Inc, \\ ${ }^{4}$ Department of Medicine, University of Florida, \\ ${ }^{5}$ Soroka Medical Center, Ben-Gurion University, Beer-Sheva, Israel, \\ ${ }^{6}$ Massachusetts General Hospital Cancer Center and Department of Medicine, Harvard Medical \\ School, \\ ${ }^{7}$ Departments of Dermatology and Pathology, and Clinical Cancer Genomics Laboratory, \\ University of California, San Francisco, \\ ${ }^{8}$ Department of Pathology, Immunology and Laboratory Medicine, University of Florida, \\ ${ }^{9}$ Department of Bioengineering and Therapeutic Sciences, University of California, San Francisco, \\ 10University of Colorado, \\ ${ }^{11}$ University of California, San Diego, \\ ${ }^{12}$ Department of Internal Medicine, University of California, Davis, \\ ${ }^{13}$ Co-corresponding authors.
}

\begin{abstract}
PURPOSE: While patients with advanced-stage non-small cell lung cancers (NSCLCs) harboring $M E T$ exon 14 skipping mutations (METex14) often benefit from MET tyrosine kinase inhibitor (TKI) treatment, clinical benefit is limited by primary and acquired drug resistance. The molecular basis for this resistance remains incompletely understood.
\end{abstract}

Correspondence to: Collin M. Blakely (Collin.blakely@ucsf.edu) or Trever G. Bivona (trever.bivona@ucsf.edu), $60016^{\text {th }}$ Street, Room N232, San Francisco, CA 94143, Phone 415-502-0237. 
METHODS: Targeted sequencing analysis was performed on cell-free circulating tumor DNA obtained from 289 patients with advanced-stage METex14-mutated NSCLC.

RESULTS: Prominent co-occurring RAS-MAPK pathway gene alterations (e.g. in $K R A S, N F I$ ) were detected in NSCLCs with METex 14 skipping alterations as compared to EGFR-mutated NSCLCs. There was an association between decreased MET TKI treatment response and RASMAPK pathway co-occurring alterations. In a preclinical model expressing a canonical METex 14 mutation, KRAS overexpression or NF1 downregulation hyperactivated MAPK signaling to promote MET TKI resistance. This resistance was overcome by co-treatment with crizotinib and the MEK inhibitor trametinib.

CONCLUSION: Our study provides a genomic landscape of co-occurring alterations in advanced-stage METex 14-mutated NSCLC and suggests a potential combination therapy strategy targeting MAPK pathway signaling to enhance clinical outcomes.

\section{Keywords}

NSCLC; MET exon 14; cfDNA; RAS Pathway; Targeted Therapy

\section{Introduction:}

Somatic MET mutations leading to splicing-mediated loss of exon 14 and subsequent MET overexpression are an emerging therapeutic target present in $2-4 \%$ of lung adenocarcinomas $(1,2)$. MET tyrosine kinase inhibitor (TKI) treatment was associated with improved overall survival in a retrospective study of patients with METex 14-mutated NSCLC (3). In ongoing prospective studies, response rates of $32 \%$ to the multi-kinase inhibitor crizotinib, $42 \%$ to the MET TKI tepotinib, and up to $71 \%$ for treatment-naïve patients to the MET TKI capmatinib have been reported (4-6). Crizotinib has recently received FDA breakthrough designation for use in the treatment of METex14-mutated NSCLC.

While MET remains an attractive therapeutic target, both primary and acquired resistance limit the long-term survival of patients with METex14-mutated NSCLC. Second-site MET mutations and downstream signaling reactivation via acquired $K R A S$ amplification have been reported at acquired resistance to MET TKI therapy, and may inform treatment decisions (7-10). By contrast, the mechanisms mediating both primary MET TKI resistance and tumor cell persistence during initial MET TKI treatment remain largely undefined, as does the full landscape of alterations promoting acquired resistance.

Recent studies show that advanced-stage NSCLCs often harbor multiple oncogenic alterations, which may impact response to targeted therapies (11-13). A prior 28-patient cohort describing co-occurring genomic alterations as measured by tissue biopsy demonstrated variability in frequency of co-occurring alterations between METex14mutated NSCLC and NSCLC driven by other genomic alterations (14). Analysis of cell-free circulating tumor DNA (cfDNA) utilizing next-generation sequencing (NGS) provides another avenue to describe the genomic landscape within a cancer patient and offers the potential to capture genomic changes reflecting heterogeneity across distinct metastatic tumor sites $(11,15)$. A more detailed understanding of the mutational landscape that co- 
exists with oncogenic $M E T$ alterations in NSCLC may facilitate an improved understanding of the determinants of MET TKI response and identify rational polytherapy strategies to improve clinical outcomes.

Here, we describe the spectrum of co-occurring genomic alterations observed within the cfDNA of patients with METex 14-mutated, advanced-stage NSCLC and identify prominent co-alteration of RAS pathway genes as a contributing factor to disease progression.

\section{Methods:}

Patients:

This study and waiver of written consent were approved by the Institutional Review Board (IRB) at the University of California, San Francisco. The conduct of this research was in accordance with the U.S. Common Rule. The cfDNA analysis included 332 consecutive samples from 289 patients with advanced (stage IIIB/IV) non-small cell lung cancer with a METex14 mutation obtained between October 2015 and March 2018, and 1653 consecutively tested samples from 1489 patients with EGFR-mutated NSCLC (L858R and del19) obtained between April 2016 and May 2017, as well as previously published (11) cohorts of EGFR wild type and TKI-naïve EGFR-mutated NSCLC (Supplemental Table 1).

\section{Cell lines and reagents:}

$\mathrm{Ba} / \mathrm{F} 3$ cells were purchased from ATCC (ATCC $® \mathrm{HB}-283^{\mathrm{TM}}$ ) and maintained in culture for a total of approximately 2-3 months in DMEM supplemented with $1 \mathrm{ng} / \mathrm{mL} \mathrm{IL-3}$

(Peprotech). Mycoplasma testing was not performed. Retrovirus was generated using TransIT-LT1 transfection reagent (Mirus). Cells were infected with filtered retrovirus, expressing either the ORF control mCherry, human wildtype MET, or human MET ${ }^{e x 14}$ in a pBABE-puro vector backbone as previously described (9) and selected in puromycin ( $2 \mu \mathrm{g} /$ $\mathrm{mL}$ ). Expression was confirmed by immunoblotting. KRAS-overexpressing cells were obtained by retroviral infection with a pBABE-hygro $K R A S 4 B$ construct and selected in hygromycin $(800 \mu \mathrm{g} / \mathrm{mL})$. Knockdown of $\mathrm{NF} 1$ was achieved by lentiviral transduction of the following sequence: 5 '-

CCGGGCCAACCTTAACCTCTCTAATCTCGAGATTAGAGAGGTTAAGGTTGGCTTTT TG-3', expressed from a pLKO.1-hygro plasmid backbone (Addgene \#24150). Three days after lentiviral transduction, cells were selected via treatment with hygromycin B and knockdown was confirmed by immunoblotting. All drugs were purchased from Selleck Chemicals.

\section{Transformation and cell proliferation assays:}

Transformation assay was performed by removing IL-3 through centrifugation and adding $50 \mathrm{ng} / \mathrm{mL}$ human HGF (Peprotech 100-39H). For proliferation assays cells were seeded in 96-well plates at 5,000 cells/well and the following day were exposed to crizotinib (Selleck Chemicals, \#S1068) at 0 to $10 \mu \mathrm{M}$ and/or trametinib (Selleck Chemicals, \#S2673) at 0.01 $\mu \mathrm{M}$. After 72 hours of drug exposure, CellTiter-Glo (Promega) reagent was added and luminescence was measured on a Spectramax spectrophotometer (Molecular Devices, 
Sunnyvale, CA, USA) according the manufacturer's instructions. Data are presented as percentage of viable cells compared with control cells (vehicle treatment).

\section{Immunoblotting:}

Cells were washed in PBS and lysed with $25 \mathrm{mM}$ Tris-HCL (pH 7.6), $150 \mathrm{mM} \mathrm{NaCl}, 1 \%$ NP-40, $1 \%$ sodium deoxycholate, $0.1 \%$ SDS supplemented with Halt Protease Inhibitor Cocktail (Thermo Fisher Scientific) and Halt Phosphatase Inhibitor Cocktail (Thermo Fisher Scientific). Lysates were separated in a 4\%-15\% SDS-PAGE gel and transferred onto a nitrocellulose membrane (Bio-Rad). Membranes were blocked with $5 \%$ fetal bovine serum (FBS) in Tris-buffered saline (TBS) containing $0.1 \%$ Tween and incubated with the appropriate antibodies. Detection was performed via ECL Prime (Amersham Biosciences). Antibodies against the following were obtained from Cell Signaling Technology (Danvers, MA, USA) and were used at a dilution of 1:1000: MET (\#3148), p-MET Y1349 (\#3121), pMEK S217/221 (\#9121), ERK1/2 (\#3493), p-ERK1/2 T202/Y204 (\#9106), HSP90 (\#4874), PARP (\#9546), NF1 (\#14623), horseradish peroxidase (HRP)-conjugated antimouse (\#7076) and HRP-conjugated anti-rabbit (\#7074). The following antibody was obtained from EMD Millipore (Burlington, MA, USA): RAS (05-516, 1:2000 dilution). Detection was performed via ECL Prime (Amersham Biosciences).

\section{Cell-free DNA analysis:}

Samples were shipped to a Clinical Laboratory Improvement Act (CLIA)-certified, College of American Pathologists-accredited laboratory (Guardant Health, Redwood City, CA). cfDNA was extracted from whole blood collected in 10-mL Streck tubes. After double centrifugation, 5-30 ng of cfDNA was isolated for digital sequencing of either a 70 or 73gene panel (Supplementary Table 2) as previously described (16). Only those genes in common to these two panels were included in subsequent analysis. Nonsynonymous mutations were further processed with the $\mathrm{R}$ statistical computing program (version 3.3). Variants with unknown or neutral predicted functional significance were filtered prior to analysis as previously described (11) to include those with known impact on gene function within the Cosmic (17), GENIE (18,19), and ClinVar (20) databases. Those remaining with unknown functional impact after review of these databases were included if with predicted functional impact utilizing the Mutation Assessor (version 3) algorithm (21). Mutations previously reported as associated with clonal hematopoiesis were also excluded (22). Assignment as clonal or subclonal was performed by normalized mutational allele frequency to percentage detected using a cut off of 0.2 as previously described (11). Residue numbering was standardized to MET UniProtKB-P08581.

\section{Next Generation Sequencing:}

Tumor sample next generation sequencing (NGS) was performed in CLIA-approved laboratories. The Foundation One and Foundation ACT assays are commercially available assays which were used in the clinical standard-of-care setting. The UCSF500 assay sequences 479 cancer-associated genes to target 200X coverage, utilizing sequencing of a PBMC sample, target 100X coverage, as a control (23). The University of Florida GatorSeq NGS assay, utilized for both tumor tissue and PBMC analysis, performs sequencing of 76 cancer-associated genes with target 500X coverage (Supplemental Table 2). Germline 
mutations were subtracted utilizing sequencing of buccal swab samples to a target depth of $100 X$.

\section{Droplet Digital PCR:}

Isolated genomic DNA extracted from FFPE was amplified using ddPCR Supermix for Probes (Bio-Rad) using KRAS and MET assays (PrimePCR ddPCR Mutation Assay, Bio$\mathrm{Rad}$, and custom-designed). DNA template $(8 \mu \mathrm{L})$ was added to $10 \mu \mathrm{L}$ of ddPCR Supermix for Probes (Bio-Rad) and $2 \mu \mathrm{L}$ of the primer/ probe mixture. This $20-\mu \mathrm{L}$ reaction mix was added to a DG8 cartridge together with $70 \mu \mathrm{L}$ of Droplet Generation Oil for Probes (Bio$\mathrm{Rad})$ and used for droplet generation. Droplets were then transferred to a 96-well plate (Eppendorf) and then thermal cycled with the following conditions: 5 minutes at $95^{\circ} \mathrm{C}, 40$ cycles of $94^{\circ} \mathrm{C}$ for 30 seconds, $55^{\circ} \mathrm{C}$ for 1 minute followed by $98^{\circ} \mathrm{C}$ for 10 minutes (ramp rate $2^{\circ} \mathrm{C} /$ second). Droplets were analyzed with the QX200 Droplet Reader (Bio-Rad) for fluorescent measurement of FAM and HEX probes. Gating was performed based on positive and negative controls, and mutant populations were identified. The ddPCR data were analyzed with QuantaSoft analysis software (Bio-Rad) to obtain fractional abundance of the mutant DNA alleles in the wild-type (WT)/normal background. The quantification of the target molecule was presented as number of total copies (mutant plus WT) per sample in each reaction. Fractional abundance is calculated as follows: F.A. $\%=(\mathrm{Nmut} / \mathrm{Nmut}+$ Nwt) $\times 100$ ), where Nmut is number of mutant events and Nwt is number of WT events per reaction. Multiple replicates were performed for each sample. ddPCR analysis of normal control genomic DNA (gene fragment obtained from IDT) and no DNA template (water) controls was performed in parallel with all samples, including multiple replicates as contamination-free controls.

\section{Statistical Analysis:}

Pairwise sample group comparisons for cfDNA analysis were carried out using a two-tailed Fisher's exact t-test, with Benjamini-Hochberg correction for multiple comparisons, using a false discovery rate of less than 0.2. For cell viability curves, comparisons were performed using the two-sided student t-test, with significance threshold of $p$-value $<0.05$.

\section{Results:}

\section{Co-occurring genomic alterations are common in advanced-stage METex14-mutated lung cancer}

We analyzed a cohort of 289 patients with advanced-stage NSCLC who had a METex14 mutation identified upon cfDNA analysis of 68 cancer-relevant genes using a clinically validated assay (Guardant360). This is the largest reported cohort to-date describing the genomic landscape of advanced-stage METex14-mutated NSCLC. We evaluated the frequency with which METex14 mutations co-occur with other cancer-associated mutations $(11,16)$. To focus our analysis on co-occurring mutations with potential functional impact, synonymous mutations and those with predicted neutral or unknown functional impact were excluded, as previously described (11), as were mutations previously associated with clonal hematopoiesis (22) (Supplemental Figure S1). 86.5\% of samples contained co-occurring genomic alterations, with a mean of 2.74 alterations per sample (range $0-22$ ), in addition to 
the METex 14 mutation. We use the term genomic alterations here to include both gene mutations/rearrangements and copy number gain as detected by cfDNA. The most commonly altered genes, co-occurring with the METex 14 mutation in at least $10 \%$ of patients, were TP53 (49.5\% of patients), EGFR (16.3\%), NF1 (neurofibromatosis-1) (15.6\%), BRAF (10.7\%), and $C D K 4(10.4 \%)$. Additional MET gene alterations were also common in this patient population, in which $9.3 \%$ of patients had co-occurring $M E T$ copy number gain and $12.1 \%$ had a co-occurring MET mutation (Figure 1A).

Seventeen of 34 second-site $M E T$ mutations were located in the tyrosine kinase domain. All identified $M E T$ second-site mutations, regardless of predicted functional impact, were included in this analysis. Of these, fourteen (G1163R, L1195V/F, F1200I, D1228H/N/Y, and $\mathrm{Y} 1230 \mathrm{H} / \mathrm{S}$ ) were located at residues previously associated with MET TKI resistance (79,25-27). Nine of these occurred in patients with known prior MET TKI exposure and five in patients with unknown prior treatment history. The remaining three mutations (H1094Y, R1336W, and I1084L) occurred in patients without available prior treatment history. While the METH1094Y mutation is known to lead to MET activation (28), the effects of the other two MET mutations remain uncharacterized.

The co-occurrence of other established oncogenic driver alterations ( $K R A S, E G F R, A L K$, ROS-1, BRAF) was uncommon except for the presence of activating KRAS mutations in $5.2 \%$ of patients $(\mathrm{G} 12 \mathrm{C} / \mathrm{D} / \mathrm{S} / \mathrm{V} 3.5 \%, \mathrm{G} 13 \mathrm{C} 1 \%$, Q22K $0.3 \%$, and Q61H $0.3 \%)$, canonical EGFR-activating mutations in 3.5\% (del19 3.1\%, L858R 0.7\%, T790M 2\%), and an $A L K$ gene rearrangement in $0.7 \%$. In addition, a $H E R 2$ exon 20 insertion was detected in one patient. In a patient with known clinical outcomes data, with both EGFR del19/EGFR T790M mutations and a METex14 mutation, there was partial response (RECIST 1.1) to treatment with the EGFR TKI osimertinib, which lasted 13.8 months. The remaining alterations detected in $K R A S, E G F R, A L K, R O S-1$ and $B R A F$ reflected mutations which are not canonical-driver alterations as listed above and/or reflected copy number gain. While in the overall dataset the METex14 mutation detected was predominantly clonal (80.6\% of samples, defined as normalized MAF $>0.2$ ), in samples with a detectable co-occurring oncogenic driver alteration the METex14 alteration was more likely to be subclonal (21.4\% of samples clonal, p-value <0.0001). The converse was also true; co-occurring established oncogenic driver mutations that were detected were more likely to be clonal than the other detected co-occurring genomic alterations $(68.6 \%$ versus $46.3 \%$, $\mathrm{p}$-value $=0.0144)$ (Supplemental Figure S2).

\section{RAS pathway alterations are more common in METex14-mutated NSCLC than in EGFR- mutated NSCLC}

To understand how the genomic landscape in advanced-stage METex14-mutated NSCLC compares to NSCLCs with a different targetable oncogenic driver mutation associated with high upfront response rates to TKI therapy, we used identical cfDNA profiling to compare a cohort of patients with known METex14-mutated NSCLC to a previously unpublished, independent cohort of 1653 samples from 1489 patients with advanced-stage EGFR-mutant (del19, L858R) NSCLC (Supplemental Table 1). This comparison demonstrated differential frequency of co-occurring genomic alterations in 17 genes (Figure 2A). In the METex14- 
mutated cohort, co-occurring alterations in NF1, CDK4, STK11, ALK, KRAS, ATM, $C D K N 2 A, N R A S$, TSC1, and ESR1 were more commonly identified. In the EGFR-mutated cohort, co-occurring alterations in $A R, E R B B 2, C C N E 1$, PIK3CA, BRAF, CTNNB1, and $M Y C$ were more commonly identified, independently validating our prior findings identifying these as common co-occurring alterations in EGFR-mutated NSCLC (11).

Among the 10 genes with a greater frequency of co-occurring genomic alteration in patients with a METex14 mutation, three (NF1, KRAS, and NRAS) are key components of the RASMAPK signaling pathway. When compared to a previously published, independent cohort of 918 patients with EGFR wildtype/METex14 negative NSCLC (29), alterations in NF1 remained significantly more common in METex 14-mutated NSCLC. Genomic alterations in $K R A S$ were significantly enriched in the EGFR wildtype/METex 14 negative cohort compared to either the METex14- or EGFR-mutated cohorts, consistent with prior reported rates of $K R A S$ gene alteration in NSCLC (12) (Figure 2A).

A propensity towards genomic alterations promoting downstream hyperactivation of the RAS pathway may favor primary resistance to TKI therapy and help explain the comparatively lower TKI response rates in METex14-mutated NSCLC. Examination of the subset of cfDNA samples obtained from patients with METex 14-mutated NSCLC prior to known MET TKI treatment $(\mathrm{n}=61)$ demonstrated high rates of genomic alterations capable of promoting RAS-MAPK pathway activation (37.7\% of patients, Figure 2B). Among those patients with a co-occurring RAS-MAPK pathway genomic alteration, $34.8 \%$ had more than one simultaneous alterations within this pathway (median 1, mean 1.53, range 1-5 RASMAPK genomic alterations). When compared to the subset of cfDNA samples from TKInaïve patients with $E G F R$-mutated NSCLC ( $=58)$ derived from the dataset discussed here and from a previously published patient cohort (11), there remained a trend towards more common detection of RAS-MAPK pathway alterations before treatment in METex14mutated NSCLC (37.7\% vs 19.0\%, p-value 0.0297, q-value $=0.297$ with correction for multiple hypothesis testing by Benjamini-Hochberg for FDR < 20\%) which was not present for other categories of gene alterations (Figure 2C).

\section{Both MET second-site mutations and RAS pathway alterations are newly detectable following MET TKI treatment.}

We identified twelve patients with cfDNA obtained following treatment with crizotinib and an available matched sample obtained prior to known crizotinib exposure (Figure 3A, B, Table 1). Details regarding one patient (patient \#5) in this dataset have previously been published by other groups $(7,9)$.

Newly detectable $M E T$ second-site mutations (Y1230H/S, D1228H/N, F1200I, L1195V) were detected in four of twelve patients following MET TKI treatment (Figure 3C, Table 1). While some of these mutations have been reported at acquired MET TKI resistance (7-9,2527), the METF1200I has not yet been described in a patient sample. Identification of specific acquired second-site mutations at resistance to MET TKI therapy may inform treatment decisions. MET TKIs can be classified as type I TKIs (e.g. crizotinib, capmatinib) or type II TKIs (e.g. cabozantinib) based on the kinase domain conformation to which they bind and differ in their activity against second-site MET mutations. For example, the $M E T$ 
Y1230X and D1228X mutations develop at resistance to type I MET TKIs and may predict response to subsequent type II MET TKI treatment (7-9,25-27). Conversely, the MET L1195V mutation has been reported at resistance to type II MET TKI treatment (7).

The development of acquired METF1200 mutations as a resistance mechanism to MET TKIs has previously been predicted in a preclinical drug resistance screen, in which MET F1200 mutations were the dominant resistance mechanism to a type II MET TKI and were observed, though less common, at resistance to a type I MET TKI (30). Molecular modeling studies suggest that METF1200I alters the conformation of the kinase domain such that it interferes with both the binding of type II MET TKIs within the DFG-out binding pocket, and to a lesser extent, may promote type I MET TKI resistance through disruption of an autoinhibitory MET conformation (Supplemental Figure S3) (7). Moreover, the F1200 residue is conserved across multiple tyrosine kinases, including ALK, ROS1, NTRK, and $\mathrm{ABL}$, in which mutations at the corresponding residue have been linked to TKI resistance (Supplemental Table 3) (30-36).

In contrast, parallel and downstream pathway alterations with the potential to provide alternative input for RAS-MAPK pathway signaling were newly detectable in eight of twelve patients following MET TKI treatment as compared to cfDNA samples obtained prior to MET TKI treatment (Figure 3C, Table 1). In addition to two patients with KRAS amplification, which was recently implicated in MET TKI resistance (10), an NF1 frameshift mutation, and copy number gain in EGFR and KIT were identified. In one patient with acquired KRAS amplification, addition of the MEK inhibitor trametinib to crizotinib treatment rapidly decreased detectable circulating tumor cfDNA. In the second patient with acquired $K R A S$ amplification, an activating $K R A S$ G12D mutation and amplification of the MET ligand $H G F$ were also present within a progressing lesion on crizotinib. Further details regarding the two patients with acquired $K R A S$ amplification are presented in Supplemental Figure S4. Potential bypass pathway alterations co-existed with second-site $M E T$ alterations in three of four patients with second-site $M E T$ alterations, while alterations specifically within RAS-pathway members co-occurred with only one of four patients with second-site MET alterations.

\section{MEK inhibition overcomes crizotinib resistance induced by RAS-MAPK pathway alterations}

The clinical data suggested that preexisting or acquired genomic changes leading to RASMAPK pathway activation (e.g. in $K R A S, N F 1$ ) may limit response and induce resistance to MET TKI treatment in METex 14-mutated NSCLC. In one patient with $K R A S$ amplification detectable at acquired resistance to crizotinib treatment, combination treatment off-label with both crizotinib (250 $\mathrm{mg}$ po BID) and trametinib ( $2 \mathrm{mg}$ po daily) resulted in rapid loss of both detectable METex14 and $K R A S$ amplification by cfDNA suggestive of treatment response. However, despite molecular evidence of tumor response this combination therapy was poorly tolerated in the context of overall clinical decline, with fatigue, fluid retention, and diarrhea. Despite dose reduction to trametinib $2 \mathrm{mg}$ every other day, the patient expired before radiographic response assessment (Figure S4). 
To assess the functional impact of RAS-MAPK pathway hyperactivation on sensitivity to MET TKI treatment, we engineered a new Ba/F3 cell-based system. The IL-3 dependent $\mathrm{Ba} / \mathrm{F} 3$ cell line, while not of epithelial origin, is an established system to assess oncogenic capacity and putative drug resistance mechanisms $(37,38)$. Stable expression of human METex14 in Ba/F3 cells in the presence of the MET ligand human HGF (Hepatocyte Growth Factor) induced IL-3-independent growth (Figure S5A, S5B) and increased downstream Erk phosphorylation compared to expression of wild type MET (Figure 4C, 4F). METex 14-mutant expressing cells were sensitive to treatment with crizotinib, as measured by reduced cell growth in standard cell viability assays (Figure 4A, 4D).

Overexpression of wild type $K R A S$ or knockdown of wild type NF1 in METex14expressing $\mathrm{Ba} / \mathrm{F} 3$ cells induced resistance to crizotinib (Figure 4A, 4D). Overexpression of wild type $K R A S$ increased the IC50 (inhibitory concentration of drug that decreases cell viability to $50 \%$ ) to crizotinib from $0.16 \mu \mathrm{M}$ to $1.68 \mu \mathrm{M}$ (p-value < 0.001 ) (Figure 4A, 4G) and $N F 1$ downregulation increased the IC50 to crizotinib from $0.16 \mu \mathrm{M}$ to $0.75 \mu \mathrm{M}$ (p-value $<0.001$ ) (Figure 4D, 4H). Treatment of cells harboring both METex 14 and KRAS overexpression with the combination of crizotinib and the MEK inhibitor trametinib in order to block both MET signaling and downstream MAPK pathway signaling restored sensitivity to treatment (crizotinib IC50 of $1.68 \mu \mathrm{M}$ in the absence of trametinib versus $0.25 \mu \mathrm{M}$ with trametinib co-treatment, $p$-value $<0.001$ ) (Figure 4B, 4G). Similarly, co-treatment of cells harboring both METex 14 and NF1 downregulation with both trametinib and crizotinib restored sensitivity to treatment (crizotinib monotherapy IC50 $0.75 \mu \mathrm{M}$ versus $0.18 \mu \mathrm{M}$ upon addition of trametinib, $p$-value $<0.001$ (Figure 4E, 4H). The selected trametinib dose modestly reduced but did not eliminate cell growth in the absence of crizotinib (Supplemental Figure S5). Immunoblotting demonstrated sustained Erk phosphorylation despite crizotinib treatment in samples with $K R A S$ overexpression or $N F 1$ downregulation, which was abrogated by the addition of trametinib (Figure 4C, 4F). In both genomic contexts, combination treatment was associated with increased levels of cleaved PARP, indicative of apoptosis, which was absent with monotherapy (Figure 4C, 4F).

\section{Discussion:}

The challenge of therapeutic resistance in patients harboring METex14 mutations is of increasing clinical relevance given the emergence of MET-targeted therapies into the clinic. While off-label use of MET TKI therapy has demonstrated clinical activity, objective reported response rates of approximately 30-70\% as reported in early studies (4-6) are generally lower than those seen in response to TKI treatment in NSCLC driven by other canonical oncogenes (EGFR, ALK), where response rates greater than $80 \%$ have been reported $(39,40)$.

RAS-MAPK pathway hyperactivation has an established role in promoting resistance to EGFR, ALK, BRAF, and ROS1 targeted therapies via diverse mechanisms including $K R A S$ amplification and $K R A S, B R A F$, and $N F 1$ mutations (41-49). While $K R A S$ amplification has also recently been reported at acquired MET TKI resistance in METex14-mutated NSCLC (10), the broader role of compensatory genomic events providing signaling pathway re-activation remains less well-understood in METex14-mutated NSCLC. Here, we describe 
frequent co-occurring RAS-MAPK pathway alterations in METex14-mutated NSCLC as compared to EGFR-mutated NSCLC. RAS-MAPK pathway alterations were detected even in TKI-naïve patients; our preclinical and clinical data suggest these co-occurring alterations may promote resistance to MET TKI therapy. More specifically, RAS-MAPK pathway alterations when present as co-occurring genomic events in METex14-mutated NSCLC prior to MET TKI treatment may induce not only primary resistance but also contribute to tumor cell persistence, thus limiting response magnitude and potentially duration of response to initial treatment. This notion is supported by our findings in the $\mathrm{Ba} / \mathrm{F} 3$ preclinical system we engineered. We also describe the spectrum and relative frequencies of newly detectable genomic alterations following MET TKI treatment as measured by cfDNA, which included alterations within the RAS-MAPK pathway or within RTKs upstream of the RAS-MAPK pathway (50) in two thirds of patients.

While our reported dataset is limited by lack of complete clinical outcomes data it highlights the importance of developing future patient cohorts incorporating outcomes data to link the understanding of the genomic landscape to treatment response and prognosis, particularly for those patients with less common or emerging driver mutations. The recently reported association between MET protein expression and response to MET TKI therapy in METex14-mutated NSCLC (51) additionally raises the question of future need for assays incorporating information regarding protein expression to assist with therapeutic decisionmaking in this patient population and warrants prospective study.

Clinically, while many MET second-site mutations acquired during type I MET TKI (e.g. crizotinib) treatment may be overcome by use of type II MET TKIs (e.g. cabozantinib) (79), the genomic alterations favoring RAS-MAPK pathway activation described here will likely require a combination therapy strategy. In our METex 14-mutated preclinical model system, RAS-MAPK pathway hyperactivation via KRAS overexpression or NF1 downregulation induced MET TKI resistance that was overcome by the addition of the MEK inhibitor trametinib. Changes in the cfDNA profile suggested early evidence of molecular response to treatment with a crizotinib and trametinib combination therapy in a patient with acquired $K R A S$ amplification, but treatment was poorly tolerated. Future efforts to develop combination therapies against these targets will require attention to agent selection, dosing, and scheduling to achieve both tolerability and efficacy.

This study enhances the understanding of the role of co-occurring genomic alterations in METex14-mutated NSCLC, with implications for the development of personalized therapeutic strategies to enhance the initial response magnitude and duration to MET TKI and delay or overcome acquired resistance. Given the prominence of genomic alterations favoring RAS-MAPK pathway hyperactivation, the addition of a MEK or potentially an ERK inhibitor to MET TKI therapy is a promising combination therapy strategy which warrants further prospective study.

\section{Supplementary Material}

Refer to Web version on PubMed Central for supplementary material. 


\section{Acknowledgements:}

The authors acknowledge funding support from NIH / NCI U54CA224068 (to R.B.C.); R01CA227807, R01CA239604, R01CA230263 (to E.A.C.); NIH / NCI U01CA217882, NIH / NCI U54CA224081, NIH / NCI R01CA204302, NIH / NCI R01CA211052, NIH / NCI R01CA169338, and the Pew-Stewart Foundations (to T.G.B.); and the Damon Runyon Cancer Research Foundation, Doris Duke Charitable Foundation, V Foundation, and American Cancer Society to C.M.B.

Disclosures:

B.C.B is a consultant to Lilly. E.A.C. is a consultant/advisor to Celgene, Qiagen, Guardant Health and Takeda and has received research funding from Merck KgA, Ignyta, Gilead, and Daiichi Sankyo and is a shareholder in Clara Health, Illumina, Guardant Health, Tatara Therapeutics and Pacific Biosciences. C.E.M has received honoraria from Honoraria from Guardant, Takeda, and Novartis. C.M.B. is a consultant to Revolution Medicines and Jazz pharmaceuticals, and has received research funding from Novartis, AstraZeneca, MedImmune, Ignyta/Genentech, Mirati, Spectrum, and Clovis Oncology. J.S.F. is a consultant, has received research funding, and has a financial stake in Relay Therapeutics. R.B.C. is a consultant/advisory board member for Amgen, Astex Pharmaceuticals, Avidity Biosciences, BMS, Fog Pharma, Genentech, LOXO, Merrimack, N-of-one, Roche, Spectrum Pharmaceuticals, Symphogen, Taiho, and Warp Drive Bio and has received research funding from AstraZeneca and Sanofi. J.P. is a consult to AstraZeneca and Novartis, received honoraria from Genentech and Takeda, and has received research funding from Pfizer. L.B. is a consultant/advisor to Takeda, Genentech, G1 Therapeutics, LOXO, AstraZeneca, and AbbVie. T.L. has received honoraria from Foundation Medicine and research funding from Pfizer, Hengrui, and Merck. T.G.B is a consultant/advisor to Novartis, AstraZeneca, Revolution Medicines, Takeda, and Array Biopharma and has received research funding from Novartis, Revolution Medicines, and Ignyta. V.M.R. and R.B.L are employees and shareholders of Guardant Health, Inc.

\section{References:}

1. Frampton GM, Ali SM, Rosenzweig M, Chmielecki J, Lu X, Bauer TM, et al. Activation of MET via diverse exon 14 splicing alterations occurs in multiple tumor types and confers clinical sensitivity to MET inhibitors. Cancer Discov 2015;5(8):850-9. [PubMed: 25971938]

2. Comprehensive molecular profiling of lung adenocarcinoma. Nature 2014;511(7511):543-50. [PubMed: 25079552]

3. Paik PK, Drilon A, Fan PD, Yu H, Rekhtman N, Ginsberg MS, et al. Response to MET inhibitors in patients with stage IV lung adenocarcinomas harboring MET mutations causing exon 14 skipping. Cancer Discov 2015;5(8):842-9. [PubMed: 25971939]

4. Paik PK, Veillon R, Cortot A, Felip E, Sakai H, Mazieres J, et al. Phase II study of tepotinib in NSCLC patients with METex14 mutations. J Clin Oncol 2019;37(suppl; abstr 9005).

5. Drilon AC, J. W, Weiss J, Ou I, Camidge R, Solomon B, Otterson GA, et al. Updated Antitumor Activity of Crizotinib in Patients with MET Exon 14-Altered Advanced Non-Small Cell Lung Cancer. 2018 9/25/18; Toronta, Canada.

6. Wolf J, Seto T, Han J-Y, Reguart N, Garon EB, Groen H, et al. Capmatinib (INC280) in METAex14mutated advanced non-small cell lung cancer (NSCLC): Efficacy data from the phase II GEOMETRY mono-1 study. J Clin Oncol 2019;37(supple; abstr 9004).

7. Engstrom LD, Aranda R, Lee M, Tovar EA, Essenburg CJ, Madaj Z, et al. Glesatinib Exhibits Antitumor Activity in Lung Cancer Models and Patients Harboring MET Exon 14 Mutations and Overcomes Mutation-mediated Resistance to Type I MET Inhibitors in Nonclinical Models. Clin Cancer Res 2017;23(21):6661-72. [PubMed: 28765324]

8. Bahcall M, Sim T, Paweletz CP, Patel JD, Alden RS, Kuang Y, et al. Acquired METD1228V Mutation and Resistance to MET Inhibition in Lung Cancer. Cancer Discov 2016;6(12):1334-41. [PubMed: 27694386]

9. Lu X, Peled N, Greer J, Wu W, Choi P, Berger AH, et al. MET Exon 14 Mutation Encodes an Actionable Therapeutic Target in Lung Adenocarcinoma. Cancer Res 2017;77(16):4498-505. [PubMed: 28522754]

10. Bahcall M, Awad MM, Sholl LM, Wilson FH, Xu M, Wang S, et al. Amplification of Wild-type KRAS Imparts Resistance to Crizotinib in MET Exon 14 Mutant Non-Small Cell Lung Cancer. Clin Cancer Res 2018. 
11. Blakely CM, Watkins TBK, Wu W, Gini B, Chabon JJ, McCoach CE, et al. Evolution and clinical impact of co-occurring genetic alterations in advanced-stage EGFR-mutant lung cancers. Nat Genet 2017;49(12):1693-704. [PubMed: 29106415]

12. Jordan EJ, Kim HR, Arcila ME, Barron D, Chakravarty D, Gao J, et al. Prospective Comprehensive Molecular Characterization of Lung Adenocarcinomas for Efficient Patient Matching to Approved and Emerging Therapies. Cancer Discov 2017;7(6):596-609. [PubMed: 28336552]

13. McCoach CE, Blakely CM, Banks KC, Levy B, Chue BM, Raymond VM, et al. Clinical Utility of Cell-Free DNA for the Detection of ALK Fusions and Genomic Mechanisms of ALK Inhibitor Resistance in Non-Small Cell Lung Cancer. Clin Cancer Res 2018;24(12):2758-70. [PubMed: 29599410]

14. Awad MM, Oxnard GR, Jackman DM, Savukoski DO, Hall D, Shivdasani P, et al. MET Exon 14 Mutations in Non-Small-Cell Lung Cancer Are Associated With Advanced Age and StageDependent MET Genomic Amplification and c-Met Overexpression. J Clin Oncol 2016;34(7): 721-30. [PubMed: 26729443]

15. Russo M, Siravegna G, Blaszkowsky LS, Corti G, Crisafulli G, Ahronian LG, et al. Tumor Heterogeneity and Lesion-Specific Response to Targeted Therapy in Colorectal Cancer. Cancer Discov 2016;6(2):147-53. [PubMed: 26644315]

16. Odegaard JI, Vincent JJ, Mortimer S, Vowles JV, Ulrich BC, Banks KC, et al. Validation of a Plasma-Based Comprehensive Cancer Genotyping Assay Utilizing Orthogonal Tissue- and Plasma-Based Methodologies. Clin Cancer Res 2018.

17. Tate JG, Bamford S, Jubb HC, Sondka Z, Beare DM, Bindal N, et al. COSMIC: the Catalogue Of Somatic Mutations In Cancer. Nucleic Acids Res 2019;47(D1):D941-d7. [PubMed: 30371878]

18. Cerami E, Gao J, Dogrusoz U, Gross BE, Sumer SO, Aksoy BA, et al. The cBio cancer genomics portal: an open platform for exploring multidimensional cancer genomics data. Cancer Discov 2012;2(5):401-4. [PubMed: 22588877]

19. Gao J, Aksoy BA, Dogrusoz U, Dresdner G, Gross B, Sumer SO, et al. Integrative analysis of complex cancer genomics and clinical profiles using the cBioPortal. Sci Signal 2013;6(269):pl1. [PubMed: 23550210]

20. Landrum MJ, Lee JM, Benson M, Brown GR, Chao C, Chitipiralla S, et al. ClinVar: improving access to variant interpretations and supporting evidence. Nucleic Acids Res 2018;46(D1):D1062d7. [PubMed: 29165669]

21. Reva B, Antipin Y, Sander C. Predicting the functional impact of protein mutations: application to cancer genomics. Nucleic Acids Res 2011;39(17):e118. [PubMed: 21727090]

22. Ptashkin RN, Mandelker DL, Coombs CC, Bolton K, Yelskaya Z, Hyman DM, et al. Prevalence of Clonal Hematopoiesis Mutations in Tumor-Only Clinical Genomic Profiling of Solid Tumors. JAMA Oncol 2018.

23. Goode B, Joseph NM, Stevers M, Van Ziffle J, Onodera C, Talevich E, et al. Adenomatoid tumors of the male and female genital tract are defined by TRAF7 mutations that drive aberrant NF-kB pathway activation. Mod Pathol 2018;31(4):660-73. [PubMed: 29148537]

24. Talevich E, Shain AH, Botton T, Bastian BC. CNVkit: Genome-Wide Copy Number Detection and Visualization from Targeted DNA Sequencing. PLoS Comput Biol 2016;12(4):e1004873. [PubMed: 27100738]

25. Heist RS, Sequist LV, Borger D, Gainor JF, Arellano RS, Le LP, et al. Acquired Resistance to Crizotinib in NSCLC with MET Exon 14 Skipping. J Thorac Oncol 2016;11(8):1242-5. [PubMed: 27343442]

26. Ou SI, Young L, Schrock AB, Johnson A, Klempner SJ, Zhu VW, et al. Emergence of Preexisting MET Y1230C Mutation as a Resistance Mechanism to Crizotinib in NSCLC with MET Exon 14 Skipping. J Thorac Oncol 2017;12(1):137-40. [PubMed: 27666659]

27. Schrock AB, Lai A, Ali SM, Miller VA, Raez LE. Mutation of MET Y1230 as an Acquired Mechanism of Crizotinib Resistance in NSCLC with MET Exon 14 Skipping. J Thorac Oncol 2017;12(7):e89-e90. [PubMed: 28629543]

28. Schmidt L, Junker K, Nakaigawa N, Kinjerski T, Weirich G, Miller M, et al. Novel mutations of the MET proto-oncogene in papillary renal carcinomas. Oncogene 1999;18(14):2343-50.

[PubMed: 10327054] 
29. Blakely CM, Pazarentzos E, Olivas V, Asthana S, Yan JJ, Tan I, et al. NF-kappaB-activating complex engaged in response to EGFR oncogene inhibition drives tumor cell survival and residual disease in lung cancer. Cell Rep 2015;11(1):98-110. [PubMed: 25843712]

30. Tiedt R, Degenkolbe E, Furet P, Appleton BA, Wagner S, Schoepfer J, et al. A drug resistance screen using a selective MET inhibitor reveals a spectrum of mutations that partially overlap with activating mutations found in cancer patients. Cancer Res 2011;71(15):5255-64. [PubMed: 21697284]

31. Kodityal S, Elvin JA, Squillace R, Agarwal N, Miller VA, Ali SM, et al. A novel acquired ALK F1245C mutation confers resistance to crizotinib in ALK-positive NSCLC but is sensitive to ceritinib. Lung Cancer 2016;92:19-21. [PubMed: 26775591]

32. Hallberg B, Palmer RH. Mechanistic insight into ALK receptor tyrosine kinase in human cancer biology. Nat Rev Cancer 2013;13(10):685-700. [PubMed: 24060861]

33. Davare MA, Vellore NA, Wagner JP, Eide CA, Goodman JR, Drilon A, et al. Structural insight into selectivity and resistance profiles of ROS1 tyrosine kinase inhibitors. Proc Natl Acad Sci U S A 2015;112(39):E5381-90. [PubMed: 26372962]

34. Shah NP, Nicoll JM, Nagar B, Gorre ME, Paquette RL, Kuriyan J, et al. Multiple BCR-ABL kinase domain mutations confer polyclonal resistance to the tyrosine kinase inhibitor imatinib (STI571) in chronic phase and blast crisis chronic myeloid leukemia. Cancer Cell 2002;2(2):117-25. [PubMed: 12204532]

35. Hughes T, Saglio G, Branford S, Soverini S, Kim DW, Muller MC, et al. Impact of baseline BCR$\mathrm{ABL}$ mutations on response to nilotinib in patients with chronic myeloid leukemia in chronic phase. J Clin Oncol 2009;27(25):4204-10. [PubMed: 19652056]

36. Fuse MJ, Okada K, Oh-Hara T, Ogura H, Fujita N, Katayama R. Mechanisms of Resistance to NTRK Inhibitors and Therapeutic Strategies in NTRK1-Rearranged Cancers. Mol Cancer Ther 2017;16(10):2130-43. [PubMed: 28751539]

37. Mandanas RA, Boswell HS, Lu L, Leibowitz D. BCR/ABL confers growth factor independence upon a murine myeloid cell line. Leukemia 1992;6(8):796-800. [PubMed: 1379313]

38. Greulich H, Chen TH, Feng W, Janne PA, Alvarez JV, Zappaterra M, et al. Oncogenic transformation by inhibitor-sensitive and -resistant EGFR mutants. PLoS Med 2005;2(11):e313. [PubMed: 16187797]

39. Soria JC, Ohe Y, Vansteenkiste J, Reungwetwattana T, Chewaskulyong B, Lee KH, et al. Osimertinib in Untreated EGFR-Mutated Advanced Non-Small-Cell Lung Cancer. N Engl J Med 2018;378(2):113-25. [PubMed: 29151359]

40. Peters S, Camidge DR, Shaw AT, Gadgeel S, Ahn JS, Kim DW, et al. Alectinib versus Crizotinib in Untreated ALK-Positive Non-Small-Cell Lung Cancer. N Engl J Med 2017.

41. Hrustanovic G, Olivas V, Pazarentzos E, Tulpule A, Asthana S, Blakely CM, et al. RAS-MAPK dependence underlies a rational polytherapy strategy in EML4-ALK-positive lung cancer. Nat Med 2015;21(9):1038-47. [PubMed: 26301689]

42. Crystal AS, Shaw AT, Sequist LV, Friboulet L, Niederst MJ, Lockerman EL, et al. Patient-derived models of acquired resistance can identify effective drug combinations for cancer. Science 2014;346(6216):1480-6. [PubMed: 25394791]

43. Zhu YC, Lin XP, Li XF, Wu LX, Chen HF, Wang WX, et al. Concurrent ROS1 gene rearrangement and KRAS mutation in lung adenocarcinoma: A case report and literature review. Thorac Cancer 2018;9(1):159-63. [PubMed: 28971587]

44. Cargnelutti M, Corso S, Pergolizzi M, Mevellec L, Aisner DL, Dziadziuszko R, et al. Activation of RAS family members confers resistance to ROS1 targeting drugs. Oncotarget 2015;6(7):5182-94. [PubMed: 25691052]

45. Ohashi K, Sequist LV, Arcila ME, Moran T, Chmielecki J, Lin YL, et al. Lung cancers with acquired resistance to EGFR inhibitors occasionally harbor BRAF gene mutations but lack mutations in KRAS, NRAS, or MEK1. Proc Natl Acad Sci U S A 2012;109(31):E2127-33. [PubMed: 22773810]

46. de Bruin EC, Cowell C, Warne PH, Jiang M, Saunders RE, Melnick MA, et al. Reduced NF1 expression confers resistance to EGFR inhibition in lung cancer. Cancer Discov 2014;4(5):606-19. [PubMed: 24535670] 
47. Tricker EM, Xu C, Uddin S, Capelletti M, Ercan D, Ogino A, et al. Combined EGFR/MEK Inhibition Prevents the Emergence of Resistance in EGFR mutant Lung Cancer. Cancer Discov 2015.

48. Ercan D, Xu C, Yanagita M, Monast CS, Pratilas CA, Montero J, et al. Reactivation of ERK signaling causes resistance to EGFR kinase inhibitors. Cancer Discov 2012;2(10):934-47. [PubMed: 22961667]

49. Ho CC, Liao WY, Lin CA, Shih JY, Yu CJ, Chih-Hsin Yang J. Acquired BRAF V600E Mutation as Resistant Mechanism after Treatment with Osimertinib. J Thorac Oncol 2017;12(3):567-72. [PubMed: 27923714]

50. Pylayeva-Gupta Y, Grabocka E, Bar-Sagi D. RAS oncogenes: weaving a tumorigenic web. Nat Rev Cancer 2011;11(11):761-74. [PubMed: 21993244]

51. Guo R, Offin M, Brannon AC, Chow A, Delasos L, Somwar R, et al. MET inhibitor resistance in patients with MET exon 14-altered lung cancers. J Clin Oncol 2019;37(supple; abstr 9006).

52. Altschul SF, Gish W, Miller W, Myers EW, Lipman DJ. Basic local alignment search tool. J Mol Biol 1990;215(3):403-10. [PubMed: 2231712] 


\section{Statement of Translational Relevance:}

This report describes targeted sequencing of the largest reported cohort of advanced-stage non-small cell lung cancers (NSCLCs) with a MET exon 14 skipping (METex14) mutation. While MET tyrosine kinase inhibitors (TKIs) are active in METex14-mutated NSCLC, response rates are lower than those seen to TKI therapy in other forms of oncogene-driven NSCLC. The data presented here uncover enrichment for both primary and acquired RAS-MAPK pathway alterations in METex14-mutated NSCLC, events that may limit initial response magnitude or duration to MET TKI treatment. Combined MET plus MEK inhibitor treatment can overcome RAS-MAPK pathway-mediated resistance, suggesting a novel polytherapy strategy for evaluation in prospective clinical trials. 


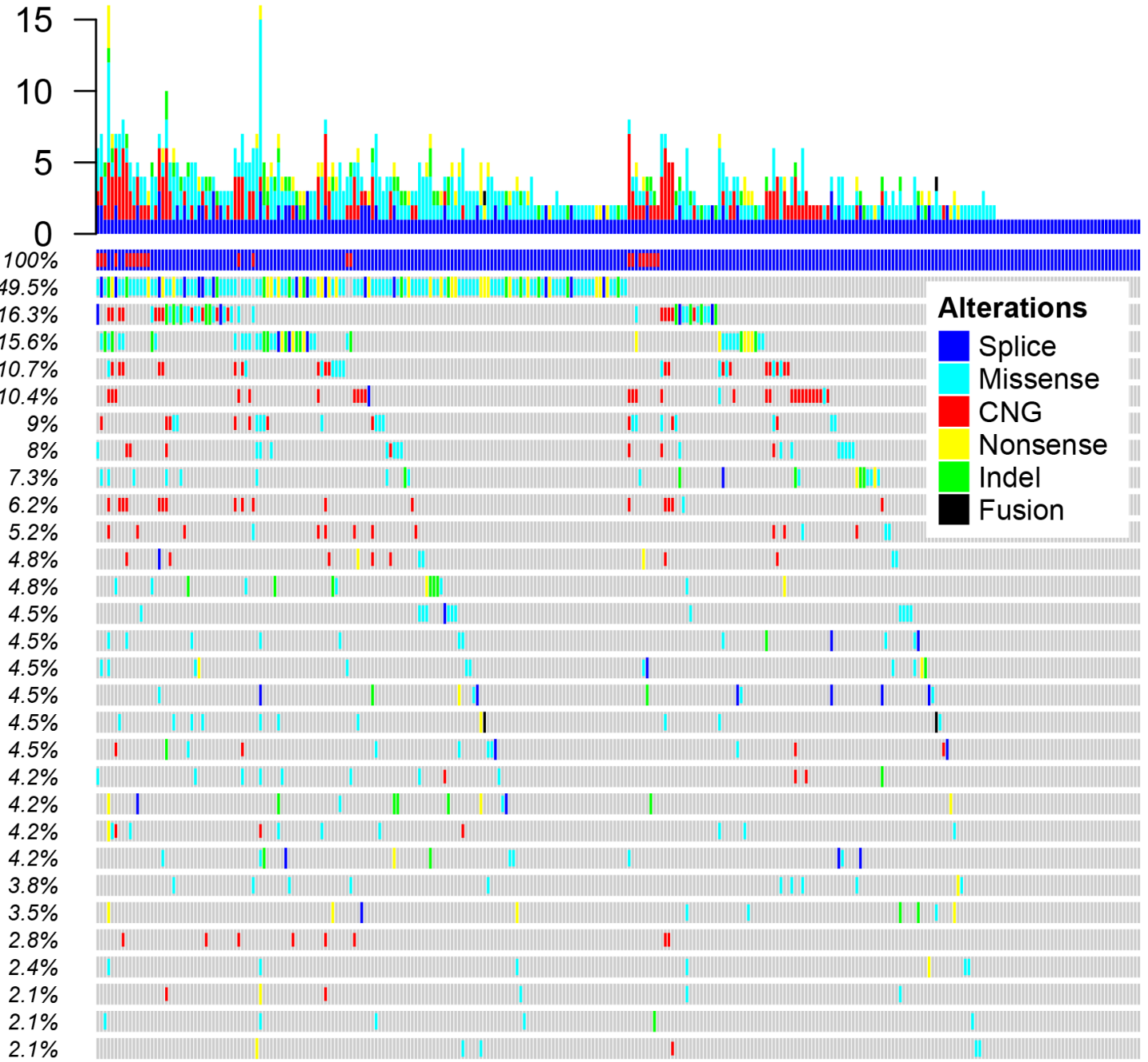

Figure 1. Co-occurring genomic alterations are common in non-small cell lung cancer (NSCLC) with a $M E T$ exon 14 mutation.

A. Distribution of co-occurring genomic alterations in a targeted list of cancer-associated genes (Supplemental Table 2) as detected by cfDNA in 332 samples from 289 patients with advanced-stage METex14-mutated NSCLC. Results are filtered to exclude synonymous variants, variants predicted to result in an unknown or neutral function impact (via COSMIC, GENIE, ClinVar, and mutation assessor prediction algorithms) and mutations previously reported as associated with clonal hematopoiesis. Only genomic alterations occurring at a $2 \%$ or greater frequency are displayed. CNG, copy number gain. 
A
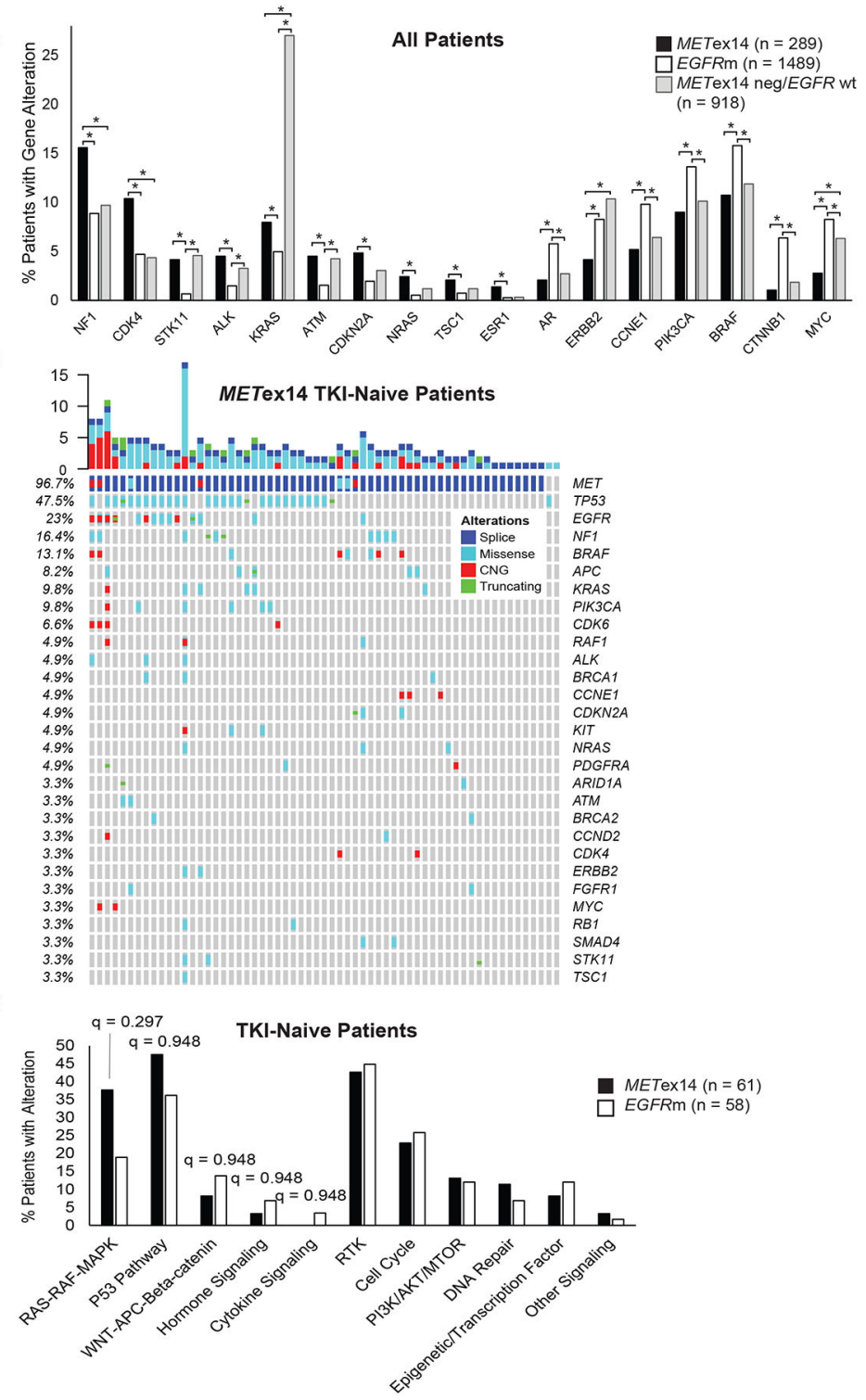

Figure 2. RAS-MAPK pathway alterations are common in METex14-mutated NSCLC

A. Comparative frequency of genomic alterations as measured by cfDNA in a cohort of advanced-stage METex14 NSCLC patients (n=289) compared to an independent cohort of patients $(\mathrm{n}=1489)$ with a known canonical $E G F R$ activating mutation (EGFR exon 19 deletions, EGFR L858R). A previously published independent cohort (11) of cfDNA from patients without either a canonical EGFR-activating mutation or METexon14 mutation (METex14 neg/EGFR wildtype, $\mathrm{n}=918$ ) is shown for comparison. Gene alterations with a statistically significant difference between METex14-mutated and EGFR-mutated NSCLC are displayed. q-values were calculated using Benjamini-Hochberg correction for false discovery rate $<0.2$, with significant differences marked by an asterisk $\left(^{*}\right)$. B. Spectrum of gene alterations detectable by cfDNA in the subset of METex14-mutated NSCLC patients $(\mathrm{n}=61)$ without prior MET TKI treatment. Genomic alterations with a frequency of greater than $2 \%$ displayed. C. Genomic alterations detectable by cfDNA in the subset of patients 
with METex 14-mutated NSCLC without prior MET TKI treatment $(\mathrm{n}=61)$ as compared to the subset of patients with EGFR-mutated NSCLC without prior EGFR TKI treatment (n = 58). q-values $>0.95$ not shown. CNG, copy number gain. 
A

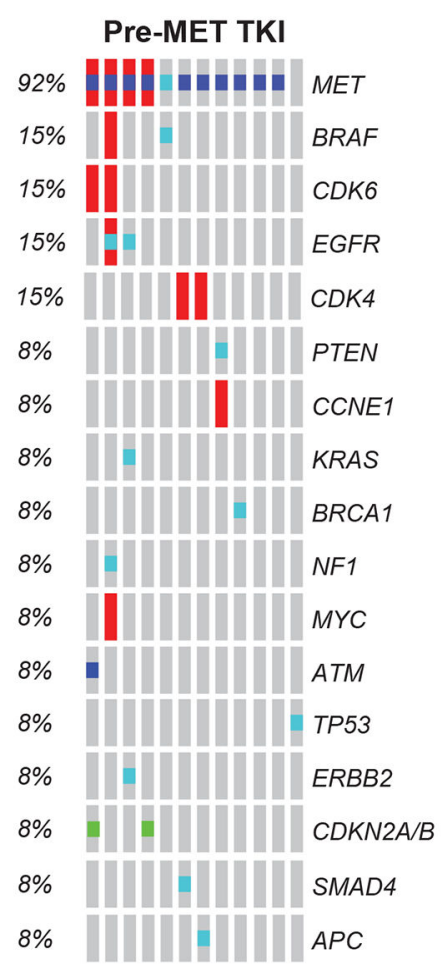

B

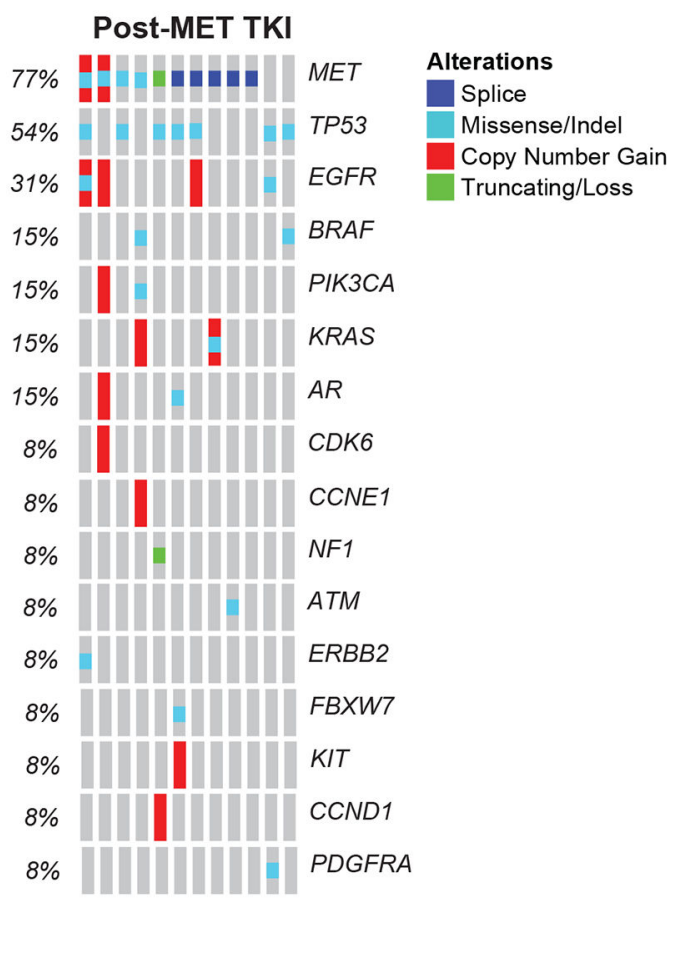

C

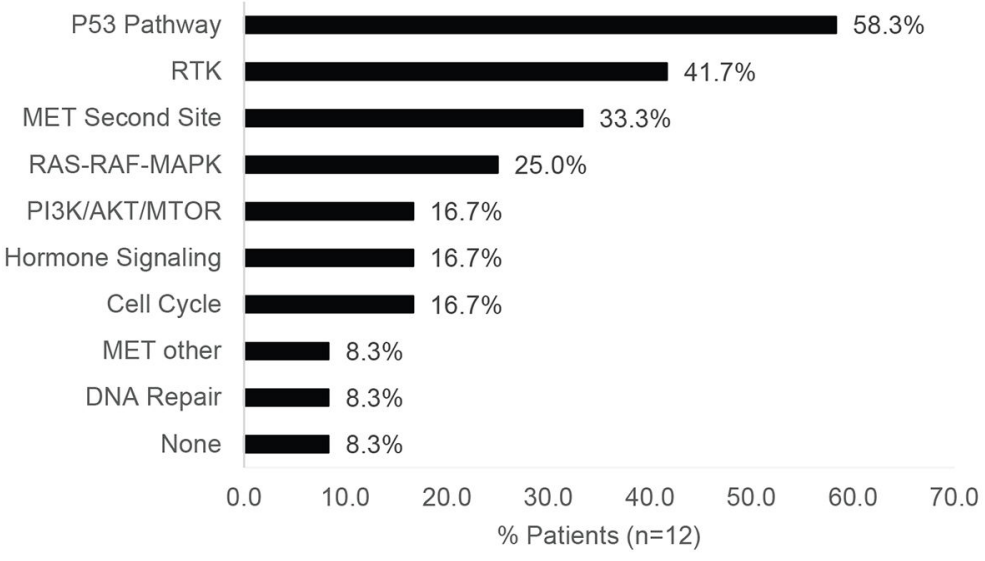

Figure 3. MET second-site and bypass pathway alterations are newly detectable after MET TKI treatment.

Oncoprints show detectable genomic alterations by in paired samples from 12 patients, obtained either (A) before known MET TKI exposure or (B) after known MET TKI exposure. All samples reflect the results of cfDNA analysis (Guardant360), with the exception of three patients for whom only tissue NGS was available pre-MET TKI. Genes not common to the cfDNA panel were excluded from analysis. Additional details included in Table 1. C. Spectrum of newly detectable genomic alterations following MET TKI exposure by functional category. 
A

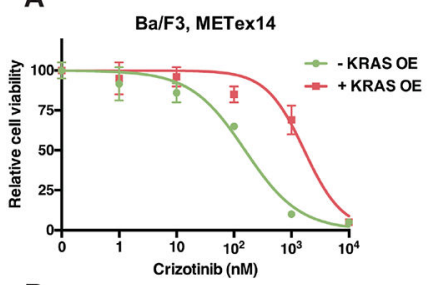

B

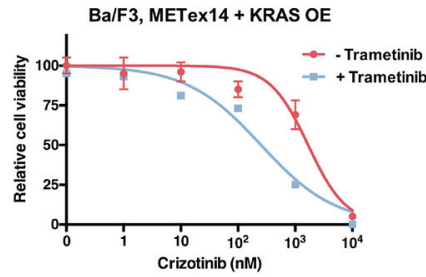

D

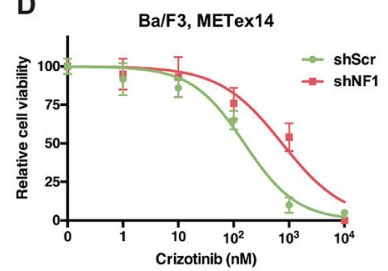

E Ba/F3, METex14 + NF1 KD

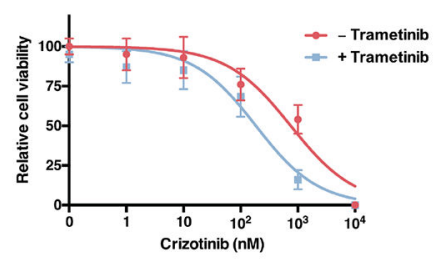

G

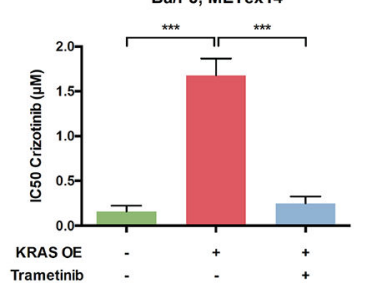

C

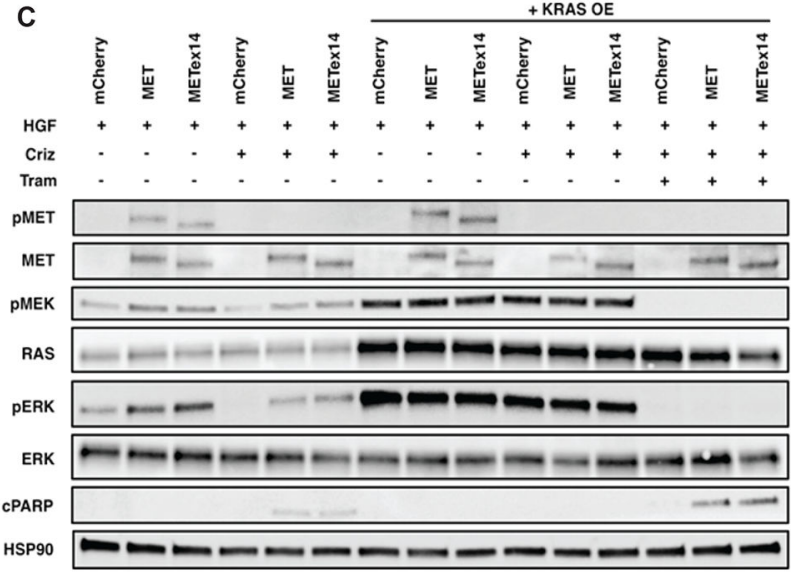

$\mathbf{F}$

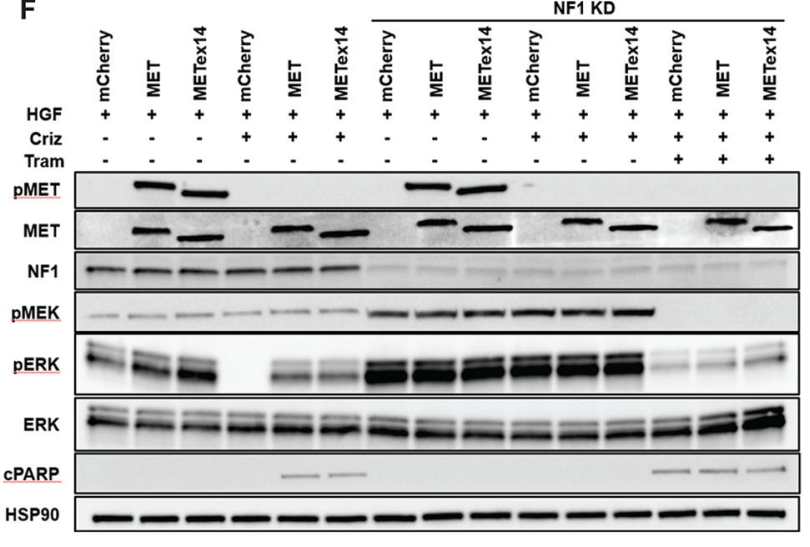

H

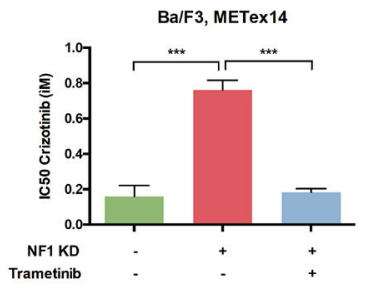

Figure 4. KRAS overexpression or NF1 downregulation promotes MET TKI resistance that is overcome by combined crizotinib and trametinib polytherapy in METex14-mutated preclinical models.

A. Cell viability curves demonstrating a shift in the half maximal inhibitory concentration (IC50) to crizotinib with overexpression of wild type KRAS in MET exon 14-mutant expressing $\mathrm{Ba} / \mathrm{F} 3$ cells. The cells were grown in culture with HGF supplementation (50 ng/ $\mathrm{mL}$ ). B. Cell viability curve for crizotinib treatment in $\mathrm{Ba} / \mathrm{F} 3$ cells with both METex 14 expression and wild-type $K R A S$ overexpression (KRAS OE), in the setting of treatment with trametinib at $0.01 \mu \mathrm{M}$ and supplementation with HGF $50 \mathrm{ng} / \mathrm{mL}$. The KRAS OE, trametinib negative curves in panels A and B reflect the same experimental data, displayed on two graphs for clarity. $\mathrm{C} \mathrm{Ba/F3}$ cells with stable expression of wild type MET, MET with an exon 14 skipping mutation (METex 14), or mCherry ORF control were treated with 50 
$\mathrm{ng} / \mathrm{mL}$ HGF with or without 24 hours treatment with crizotinib at $0.1 \mu \mathrm{M}$ and/or trametinib $(0.01 \mu \mathrm{M})$. Treatment with crizotinib inhibits MET phosphorylation and inhibits downstream Erk phosphorylation, with associated increase in apoptosis as measured by cleaved PARP (cPARP). KRAS overexpression (KRAS OE) restored downstream Erk phosphorylation and reduced cleaved PARP, despite crizotinib treatment. Addition of trametinib inhibited Erk phosphorylation and increased cleaved PARP, consistent with induction of apoptosis, despite the presence of KRAS overexpression. D. Cell viability curves for crizotinib-treated MET exon 14-mutant expressing Ba/F3 cells with either NF1 knockdown (shNF1) or a negative control scrambled shRNA (shScr). E. Cell viability curves for crizotinib-treated MET exon-14 mutant expressing Ba/F3 cells with NF1 knockdown, with and without addition of $0.01 \mu \mathrm{M}$ trametinib. The shNF1, trametinib negative curves in panels $\mathrm{C}$ and $\mathrm{D}$ reflect the same data displayed on two graphs for clarity. F. NF1 knockdown (NF1 KD) restores downstream Erk phosphorylation and decreases cleaved PARP in crizotinib-treated tumor cells. The addition of trametinib reduced Erk phosphorylation and restored PARP cleavage consistent with induction of apoptosis despite the presence of NF1. G. Summary graph of IC50 to crizotinib with trametinib with and without KRAS overexpression. H. IC50s of crizotinib with trametinib with or without NF1 downregulation. $* * *$ p-value $<0.001$ by student's t-test. 
Table 1

Genomic alterations in the cfDNA of patients treated with a MET TKI.

Genomic alterations identified upon targeted sequencing for cancer-associated genes in cfDNA samples obtained following known MET TKI exposure compared to results of samples obtained prior to known MET TKI exposure, with newly detected alterations in bold font. Sequencing performed via the Guardant 360 assay, unless otherwise specified. Further details for patients one and two in Supplemental Figure S4. Additional details regarding patient five have previously been published $(7,9)$. Abbreviations: CNG, copy number gain; NOS, not otherwise specified; SCC, squamous cell carcinoma.

\begin{tabular}{|c|c|c|c|c|c|}
\hline \multirow[t]{2}{*}{ Patient \# } & \multirow[t]{2}{*}{ Histology } & \multicolumn{2}{|c|}{ Sample Prior to Known MET TKI Exposure } & \multicolumn{2}{|c|}{ Sample After MET TKI Exposure } \\
\hline & & $\begin{array}{c}\text { Treatment } \\
\text { Status }\end{array}$ & Genomic Alterations & $\begin{array}{l}\text { MET TKI } \\
\text { Received }\end{array}$ & $\begin{array}{l}\text { Genomic Alterations \% } \\
\text { cfDNA/CNG }\end{array}$ \\
\hline 1 & $\begin{array}{l}\text { Lung Adeno- } \\
\text { carcinoma }\end{array}$ & Pre-treatment & $\begin{array}{l}\text { METex } 14, \text { PTENE } 43 \mathrm{Q}, \\
\text { CCNE1 CNG }\end{array}$ & Crizotinib & $\begin{array}{l}\text { METex14, BRAFR199G, CCNE1 } \\
\text { CNG, PIK3CA R38H, MET } \\
\text { Y1230S, MET F1200I, KRAS } \\
\text { CNG }\end{array}$ \\
\hline $2^{a}$ & $\begin{array}{l}\text { Lung Adeno- } \\
\text { carcinoma }\end{array}$ & Pre-treatment & METex14 & Crizotinib & METex 14, KRAS CNG \\
\hline 3 & $\begin{array}{l}\text { Lung Adeno- } \\
\text { carcinoma }\end{array}$ & $\begin{array}{l}\text { Carboplatin/ } \\
\text { pemetrexed/ } \\
\text { bevacizumab }\end{array}$ & METex14, BRCA1 R691G & Crizotinib & $\begin{array}{l}\text { METex 14, FBXW7 R689Q, AR } \\
\text { W742C, TP53 Y163S, KIT CNG }\end{array}$ \\
\hline 4 & $\begin{array}{l}\text { Lung Adeno- } \\
\text { carcinoma }\end{array}$ & Pre-treatment & $\begin{array}{l}\text { METex } 14, N F 1 \mathrm{I} 1499 \mathrm{~V}, B R A F \\
\text { CNG, } N F 1 \mathrm{R} 1534 \mathrm{Q}, E G F R \\
\text { V851A, EGFR CNG, } M E T \\
\text { CNG, CDK6 CNG, MYCCNG }\end{array}$ & Crizotinib $^{c}$ & $\begin{array}{l}\text { METex14, NF1 I1499V, CCND1 } \\
\text { CNG, TP53 N239S, TP53 R248W, } \\
\text { NF1 p.GIn2636s, } \text { MET } \\
\text { p.Ser244fs }\end{array}$ \\
\hline 5 & $\begin{array}{l}\text { Lung Adeno- } \\
\text { carcinoma }\end{array}$ & Pre-treatment & $\begin{array}{l}\text { METex } 14, M E T C N G, C D K 6 \\
\text { CNG, } A T M \text { splice site, } M D M 2 \\
\text { CNG, } C D K N 2 A / B \text { loss } b\end{array}$ & Crizotinib & $\begin{array}{l}\text { METex } 14, \text { METCNG, CDKG } \\
\text { CNG, AR CNG, PIK3CA CNG, } \\
\text { MET Y1230H, MET D1228N, } \\
\text { EGFR CNG }\end{array}$ \\
\hline & & & & Glesatinib & $\begin{array}{l}\text { METex 14, METCNG, CDK6 } \\
\text { CNG, PIK3CA CNG, } M E T \\
\text { D1228N, } \text { MET L1195V }\end{array}$ \\
\hline 6 & Lung SCC & Nivolumab & METex 14 & Crizotinib & $\begin{array}{l}\text { METex 14, EGFR CNG, TP53 } \\
\text { p.Arg156del }\end{array}$ \\
\hline 7 & $\begin{array}{l}\text { Lung Adeno- } \\
\text { carcinoma }\end{array}$ & $\begin{array}{l}\text { Carboplatin/ } \\
\text { Paclitaxel }\end{array}$ & TP53 P27L, TP53 $\mathrm{c} 375+1 \mathrm{G}>\mathrm{C}$ & Crizotinib & METex 14 \\
\hline 8 & $\begin{array}{l}\text { Lung Adeno- } \\
\text { carcinoma }\end{array}$ & $\begin{array}{l}\text { Carboplatin/ } \\
\text { pemetrexed/ } \\
\text { bevacizumab }\end{array}$ & $\begin{array}{l}\text { METex14, BRAFS273G, } M E T \\
\text { R1170* }\end{array}$ & Crizotinib & $B R A F \mathrm{~S} 273 \mathrm{G}$, TP53 V173M \\
\hline 9 & $\begin{array}{l}\text { Lung Adeno- } \\
\text { carcinoma }\end{array}$ & Unknown & $\begin{array}{l}M E T \mathrm{ex} 14, \text { METCNG, EGFR } \\
\text { K80T, ERBB2 N68S, KRAS } \\
\text { G12S }\end{array}$ & Crizotinib & $\begin{array}{l}\text { METex14, METCNG, EGFR } \\
\text { K80T, ERBB2 N68S, MET } \\
\text { L1195V, TP53 V216E, EGFR } \\
\text { CNG }\end{array}$ \\
\hline 10 & $\begin{array}{l}\text { Lung Adeno- } \\
\text { carcinoma }\end{array}$ & Unknown & $\begin{array}{l}M E T \mathrm{ex} 14, \text { METCNG, } \\
C D K N 2 A \text { p.Thr77fs }\end{array}$ & Crizotinib & $\begin{array}{l}\text { TP53 R158H, EGFR R836H, } \\
\text { PDGFRA R558H }\end{array}$ \\
\hline 11 & NSCLC NOS & Pre-treatment & $\begin{array}{l}\text { METex } 14, R E C Q L 4 \text { splice site, } \\
S M A D 4 \mathrm{Q} 224 \mathrm{X}, C D K 4 \mathrm{CNG}, \\
K M T 2 A \mathrm{CNG}, M D M 2 \mathrm{CNG}{ }^{b}\end{array}$ & Crizotinib & $\begin{array}{l}\text { METex 14, MET D1228H, TP53 } \\
\text { F270L }\end{array}$ \\
\hline 12 & $\begin{array}{l}\text { Lung Adeno- } \\
\text { carcinoma }\end{array}$ & Pre-treatment & $\begin{array}{l}\text { METex } 14, E R B B 4 \mathrm{E} 69 \mathrm{~K}, \\
C D K 4 \mathrm{CNG}, G L I 1 \mathrm{CNG}, \\
M D M 2 \mathrm{CNG}, A P C \mathrm{E} 1284 \mathrm{~K}^{b}\end{array}$ & Crizotinib & METex14, ATM N3003T \\
\hline
\end{tabular}




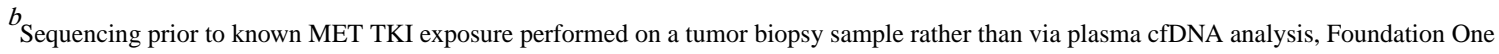
(patients 5 and 12), or Cancer-Select assay (patient 11).

${ }^{c}$ Followed by pemetrexed prior to cfDNA testing. 